\title{
INFESTAÇĀO DOMICILIAR POR TRIATOMA INFESTANS E ALGUNS ASPECTOS EPIDEMIOLÓGICOS DA TRIPANOSSOMOSE AMERICANA EM ĀREA DO ESTADO DE SÃO PAULO, BRASIL (1)
}

Oswaldo Paulo FORATTINI (2)

Edmundo JUAREZ (2)

Ernesto X. RABELLO (2)

Dino PATTOLI (2)

Renato R. CORREA (3)

\begin{abstract}
ForatrinI, O. P. et al. - Infestação domiciliar for Triatoma infestans e alguns aspectos epidemiológicos da tripanossomose americana em área do Estado de São Paulo, Brasil. Rev. Saúde públ., S. Paulo, 3(2):159-172, dez. 1969.

RESumo - São relatados os resultados das investigações sôbre epidemiologia da tripanossomose americana, levadas a efeito no Bairro da Ilha, municipio de Salto de Pirapora, Estado de São Paulo, Brasil. Em conjunto de 28 edifícios submetidos ao expurgo seletivo pela aplicação de BHC, procurou-se pesquisar a infestação por Triatoma infestans, através o método das caixas de Gómez-Núñez. O resultado revelou a persistência de edificios infestados, em proporção semelhante àquela observada antes do expurgo. Contudo, houve redução da intensidade, revelada pela queda do indice geral de infestação. A pesquisa de focos naturais do parasito mostrou a possivel existência da infecção em roedores Akodon arviculoides e Oryzomys nigripes. Levando-se a efeito xenodiagnósticos em cães e gatos, nascidos ou introduzidos logo depois do rociado seletivo, pôde-se evidenciar a persistência da transmissão, pelo menos por via congênita. Ao lado disso, observou-se a introdução precoce de animais infectados, procedentes de outras áreas. Conclui-se pela necessidade de revisão na profilaxia da doença de Chagas, baseada no simples combate aos triatomíneos pelo uso de inseticidas.
\end{abstract}

Em decorrência das medidas de profilaxia da doença de Chagas, baseadas no emprêgo sistemático de inseticidas de ação residual, têm surgido questôes que necessitam de maior esclarecimento. Entre elas, sobressae a concernente à necessidade de

Recebido para publicação em 12-8-1969.

(1) Apresentado na sessão de 4-9-1969 do Departamento de Higiene e Medicina Tropical da Associação Paulista de Medicina. Realizado com o auxílio parcial da Fundação de Amparo à Pesquisa do Estado de São Paulo (C. Med. 68/621).

(2) Da Cadeira de Epidemiologia da Faculdade de Higiene e Saúde Pública da USP - São Paulo, Brasil.

(3) Da Divisão de Combate a Vetores da Secretaria dạ Saúde do Estado de São Paulo São Paulo, Brasil. 
FORATTINI, O. P. et al. - Infestacão domiciliar por Triatoma infestans e alguns aspectos epldemiológicos da tripanossomose.. Rev. Saúde públ., S. Paulo, 8(2):159-172, dez. 1969.

avaliação dos resultados obtidos. A adoção do método seletivo (FrEITAs ${ }^{6}, 1963$ ), ou seja, a limitação do expurgo aos edificios comprovadamente infestados, ensejou o desenvolvimento de técnicas destinadas a êsse selecionamento. Em outras palavras, constitui ainda problema qual o melhor meio de diagnóstico das casas e anexos positivos. Nesse sentido, têm-se empregado sistemàticamente a inspecção domiciliar, mediante a captura manual, simples ou com o emprêgo de substâncias insetífugas. Objetivando outro processo, que fôsse mais vantajoso e uniforme, GómEZ-NúÑEZ ${ }^{\ominus}$ (1965) idealizou o emprêgo de caixas de papelão, dependuradas nas paredes, em número de duas para cada edifício. Fazendo-se o diagnóstico mediante o encontro de sinais, ou das próprias formas dos triatomíneos, êsse método tem-se mostrado altamente eficiente. Pelo menos na Venezuela, e em relação ao Rhodnius prolixus. E a tal ponto que, com êle, após a desinsetização, tem sido possível revelar a existência das casas infestadas, cuja presença não tinha sido detectada, mesmo com o emprêgo de insetífugos $\left(\mathrm{GAMBOA}^{8}, 1965\right)$.

Em vista disso, programou-se série de observações destinadas a verificar a aplicabilidade dessa técnica em nosso meio. Em trabalho anterior, foram apresentados os resultados preliminares, obtidos na comparação com a pesquisa domiciliar (Forattini, Juarez \& CorrêA ${ }^{5}, 1969$ ). Nessa ocasião pôde-se verificar que, na área trabalhada e em relação ao Triatoma infestans, o método de Gómez-Núñez mostrou eficiência comparável à da pesquisa manual simples, ou seja, sem o emprêgo de substâncias desalojantes. Restava pois, testar o seu rendimento após a realização do expurgo seletivo dos edifícios.

Ao mesmo tempo, julgou-se conveniente levar a efeito outras pesquisas. $E$ isso visando obter informações sôbre a possi- bilidade do restabelecimento ou manutenção da transmissão nessa área. Assim sendo, procurou-se executar observaçōes sôbre a existência de focos naturais da tripanossomose, ou seja, da presença do Trypanosoma cruzi em situação extrado-

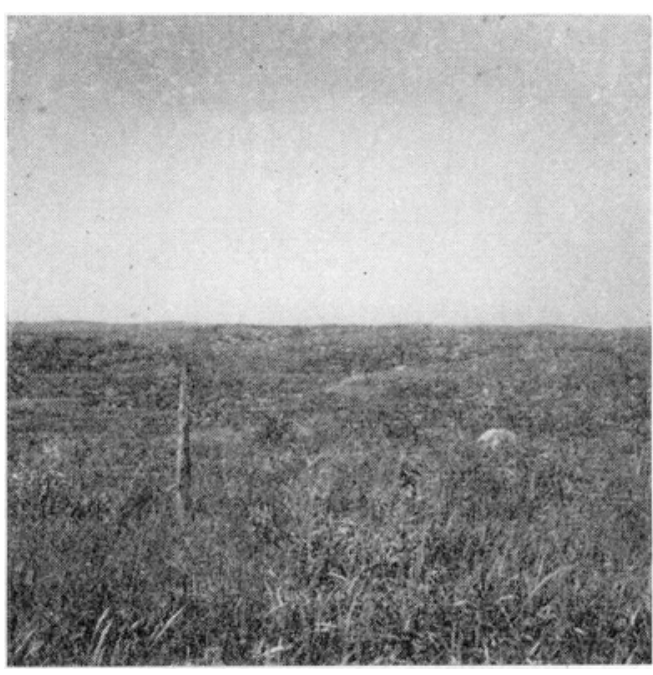

Fig. 1 - Aspecto panorâmico do Bairro da Ilha, mostrando a topografia e os conjuntos de vegetação residual de segunda formação.

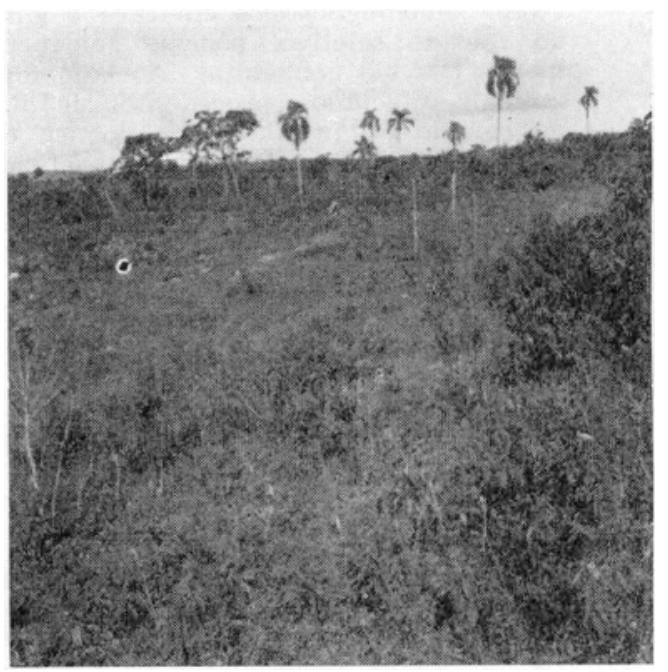

Fig. 2 - Terreno para pastagem, mostrando a abundância de vegetação arbustiva. 
FORATTINI, O. P. et al. - Infestação domiciliar por Triatoma infestans e alguns aspectos epidemiológicos da tripanossomose.. Rev. Saúde públ., S. Paulo, 3(2):159-172, dez. 1969.

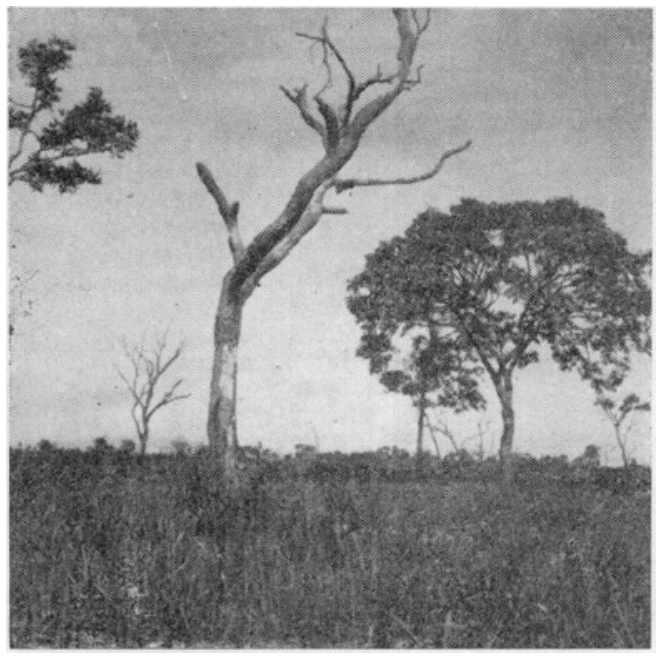

Fig. 3 - Aspecto de área de pastagem, com árvores vivas e sêcas isoladas.

miciliar. 0 mesmo aspecto foi investigado em relação ao Triatoma infestans. Ao lado disso, foram feitas investigações sôbre a possível manutenção ou introdução do parasito no ambiente domiciliar, em período imediatamente seguinte ao do expurgo. A apresentação dos resultados conseguidos, constitui o objeto dêste trabalho.

\section{REGIXO ESTUDADA}

A área trabalhada corresponde à localidade denominada Bairro da Ilha, situada no municipio de Salto de Pirapora, Estado de São Paulo. Sua localização corresponde aproximadamente às coordenadas de $23^{\circ} 40^{\prime}$ de latitude sul e de $47^{\circ} 50^{\prime}$ ' de longitude oeste. Dista cêrca de 30 quilômetros da cidade de Sorocaba.

A topografia corresponde a relêvo ligeiramente acidentado, formado por campos ondulados e alguma queda mais ou menos acentuada, correspondendo a estreitos vales onde correm os cursos de água. A altitude média local oscila ao redor de 500 metros acima do nível do mar. A vegetação predominante é arbustiva e rasteira. Faz exceção a presença de conjuntos constituídos por árvores e palmeiras de maior porte, esparsos ou aglo. merados, e que substituem a primitiva cobertura florestal. Acresce a existência de pequena agricultura, predominantemente de milho e feijão, ao lado de áreas maiores utilizadas como pastagens. Estas porém, são geralmente mal conservadas e nelas pode ser encontrada muita vegetação-arbustiva, ao lado de árvores, vivas ou sêcas, e palmeiras. As Figuras 1,2 e 3 destinam-se a fornecer idéia dêsses aspectos.

O Bairro da Ilha compreende pouco mais de meia centena de edifícios, destinados à residência dos pequenos proprietários e agregados. A quase totalidade dessas construções é de barro. Em geral, o estado de tais casas é precário. As paredes apresentam-se em mau estado de conservação e a cobertura que, em algumas é constituída por telhas de cerâmica, em outras é simplesmente de palha (Figuras 4 e 5). Os habitantes dedicam-se à pequena lavoura ou às atividades pastorís.

\section{MATERIAL E METODOS}

De acôrdo com o método de Gómez-Núnez, para a pesquisa de triatomíneos nas casas e respectivos anexos, foram instaladas caixas de papelão com as características já descritas em trabalho anterior (Forattini, Juarez \& CorrêA ${ }^{5}$, 1969). Elas tiveram uma das faces perfuradas, com aberturas circulares de tamanho e número pré-estabelecidos, e dentro delas, colocou-se papel dobrado que, por sua vez, também sofreu algumas perfuraçōes (Figuas 6 e 7). Obedecendo a critério já adotado anteriormente, êsses abrigos artificiais foram colocados, em número de dois, tanto nas casas como nos anexos; êstes últimos representados principalmente por galinheiros. Para as primeiras, escolheu-se os dormitórios, enquanto que, para os segundos, procurou-se o local preferido de pouso dos ani- 
FORATTINI, O. P. et al. - Infestação domiciliar por Triatoma infestans e alguns aspectos epldemiológicos da tripanossomose. Rev. Saúde públ., S. Paulo, 3(2):159-172, dez. 1969.



Fig. 4

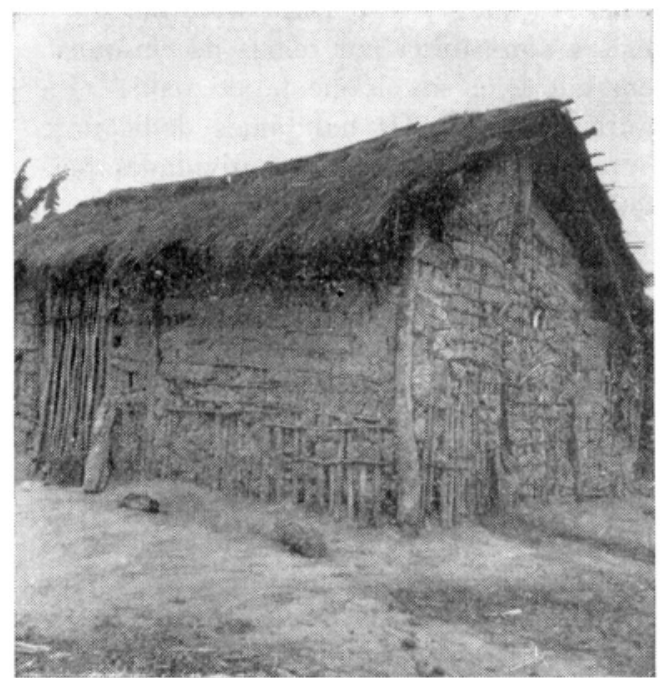

Figs, 4 e 5 - Tipos de casas do Bairro da Ilha, cobertas com telhado de cerâmica e de palha.

mais domésticos. A face perfurada foi sempre mantida voltada para a parede (Figuras 8 e 9).

Procedeu-se ao exame das caixas, mediante inspecção cuidadosa, tanto do continente como do conteúdo, êste representado pelo supracitado papel dobrado (Fi-



Fig. 6 - Caixa de Gómez-Núñez, mostrando a face perfurada que é colocada voltada para a parede.

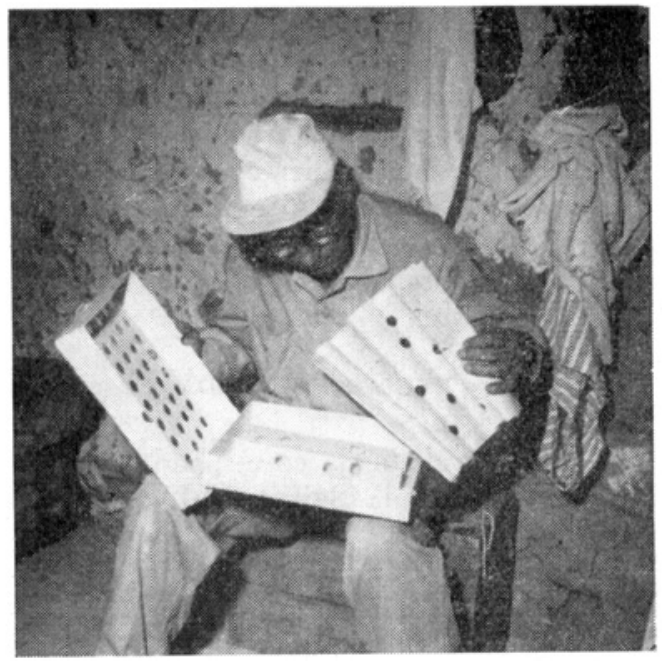

Fig. 7 - Exame da caixa de Gómez-Núnez, mostrando o papel dobrado em seu interior.

gura 7). 0 critério de positividade foi o do encontro de triatomíneos, sob a forma de ovos, ninfas ou adultos, e de vestígios fecais atribuíveis a êsses insetos. No que concerne a êsses sinais, aventou-se a hipótese de possível confusáo com fezes de baratas domésticas, existentes na localidade (Periplaneta e Blatella). Tal in- 
FORATTINI, O. P. et al. - Infestação domiciliar por Triatoma infestans e alguns aspectos epidemiológicos da tripanossomose. Rev. Saúde públ., S. Paulo, 3(2):159-172, dez. 1969.

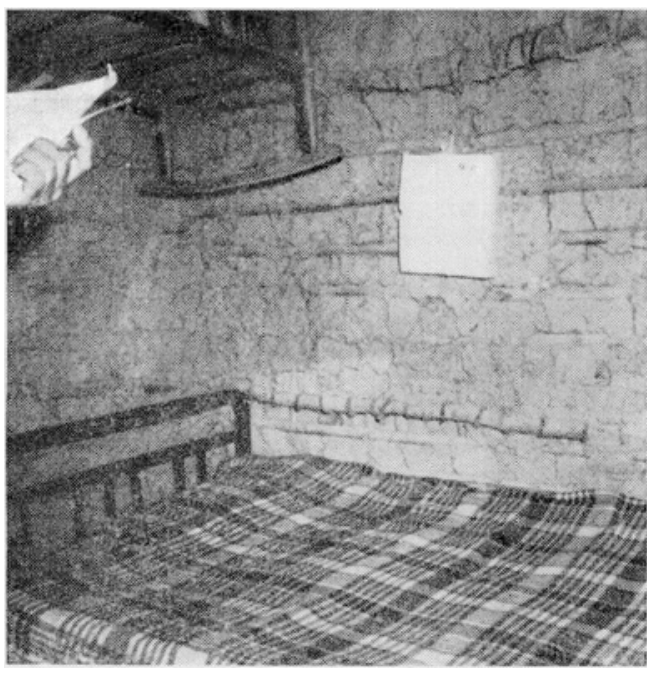

Fig. 8

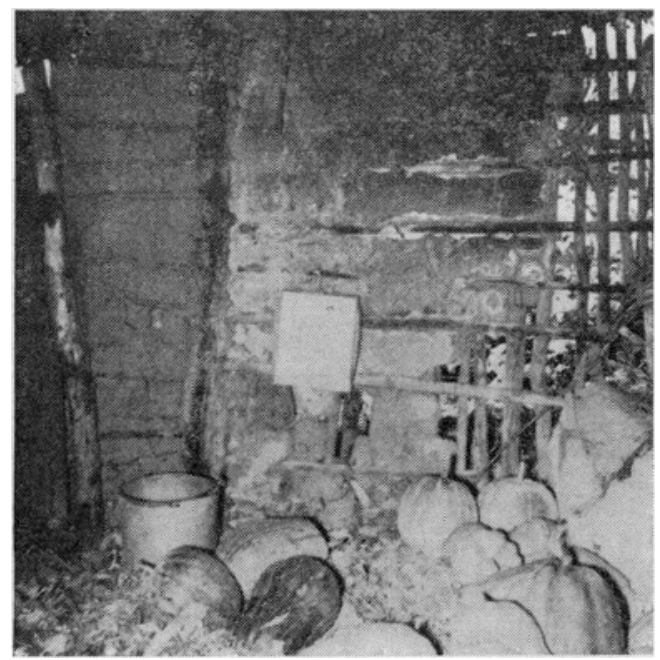

Figs. 8 e 9 - Caixas colocadas em parede de dormitório e de anexo, respectivamente.

conveniente já tinha sido assinalado por GAMBOA $^{8}$ (1965) o qual, por êsse motivo, resolveu excluir tais vestígios da leitura das caixas. Todavia, pensamos que as fezes de triatomíneos constituem marcas que não deveriam ser desprezadas. Para obviar o inconveniente de possível êrro de interpretação, resolveu-se tentar identificá-las mediante a pesquisa de san- gue oculto. Para tanto, foi empregada a técnica da benzidina com o reativo de Adler. Este constituiu de solução de ben. zidina a $2 \%$ em ácido acético a $50 \%$. Pingando-se uma ou duas gôtas sôbre o material suspeito e, logo a seguir, idêntica quantidade de água oxigenada a 20 volumes, procurou-se observar a mudan. ça de côr. Verificou-se que a reação era tanto mais rápida quanto mais recentes as fezes. Dessa maneira, se após período fixado em 15 minutos não ocorrese a alteração de tonalidade, a reação era considerada negativa. Com essa técnica, os ensaios preliminares com material fecal de baratas e triatomíneos foram satisfa. tórios. Isso permitiu a sua aplicação nas observações de campo, podendo-se assim chegar à identificação, com boa margem de segurança, dos vestígios atribuíveis aos últimos. Assim sendo, tôda caixa foi considerada positiva, desde que revelasse a presença de qualquer um dos elementos supramencionados.

Foram escolhidas 25 casas e seus respectivos anexos, êstes quando existentes, do total de 53 domicílios que constituiam - Bairro da Ilha. 0 motivo dessa escôlha obedeceu ao estabelecimento de itinerário de trabalho que permitisse examinar tôdas as caixas no mesmo dia da semana. Além disso deve-se assinalar que, no intervalo que mediou entre a desinsetização e o início das atuais observações, várias casas tinham sido abandonadas $\mathrm{e}$ demolidas, ao passo que outras foram construídas. 0 expurgo seletivo foi levado a efeito no período de 2 a 6 de dezembro de 1968, mediante o emprêgo de BHC. Atingiu êle, 15 dos supracitados domicílios, compreendendo 15 casas e 4 anexos, que tinham se revelado infestados por triatomíneos.

A colocação das caixas foi efetuada decorridos cêrca de três meses do expurgo seletivo de dezembro do ano anterior. Em seguida, procedeu-se a exames semanais, até o total de 9 semanas. Foi feita ainda, uma inspecção final, decorrido mais um mês, contado a partir da última daquelas semanas. 
FORATTINI, O. P. et al. - Infestação domiciliar por Triatoma infestans e alguns aspectos epidemlológicos da tripanossomose. $\quad$ Rev. Sauide públ., S. Paulo, 3(2):159-172, dez. 1969.

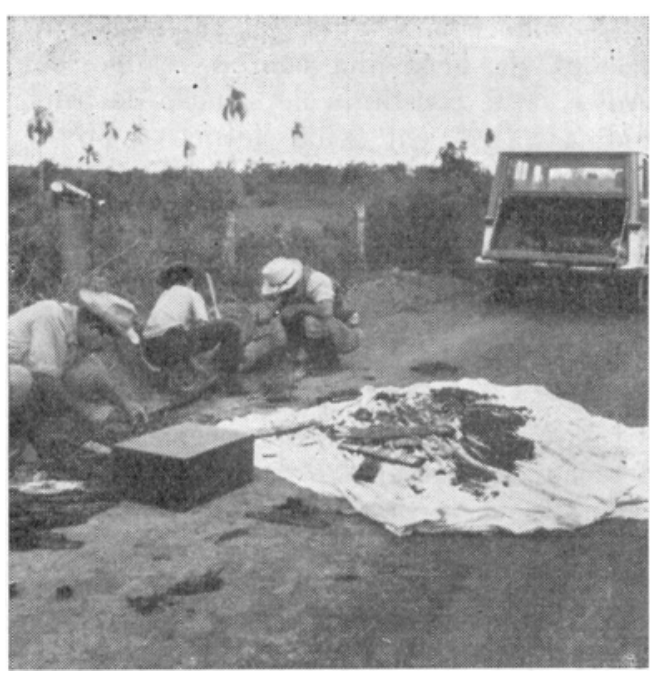

Fig. 10 - Exame de ecótopo para pesquisa de focos naturais.

No que concerne às demais observações, foram elas feitas da seguinte maneira. Em relação à presença do Trypanosoma cruzi extradomiciliar, levou-se a efeito capturas regulares de maníferos silvestres os quais eram sistemàticamente submetidos ao xenodiagnóstico. Quanto à pesquisa análoga referente ao Triatoma infestans, fêz-se a investigação sistemática do maior número possível de prováveis biótopos. Assim sendo, procurou-se pesquisar tocas e ninhos de animais, locas em pedra, ôcos de árvores, touceiras de arbustos, copas de palmeiras, cascas de árvores sêcas e mourões de cêrca, troncos de árvores caídas e outros. 0 exame foi o mais minucioso possível e realizado mediante o desbastamento manual e a inspecção do material, sôbre a superfície de um lençol branco (Figura 10). Além disso, procurou-se meio para atrair o inseto, mediante a construção de ecótopo artificial que tivesse características semelhantes à casa humana da região. Para tanto, fêz-se a instalação de pequeno galinheiro, construído de barro e colocado a 200 metros da casa infestada mais próxima. Ali foram abrigadas galinhas e todo êle foi cercado por rêde metálica a prova de predadores (Figuras 11 e 12).

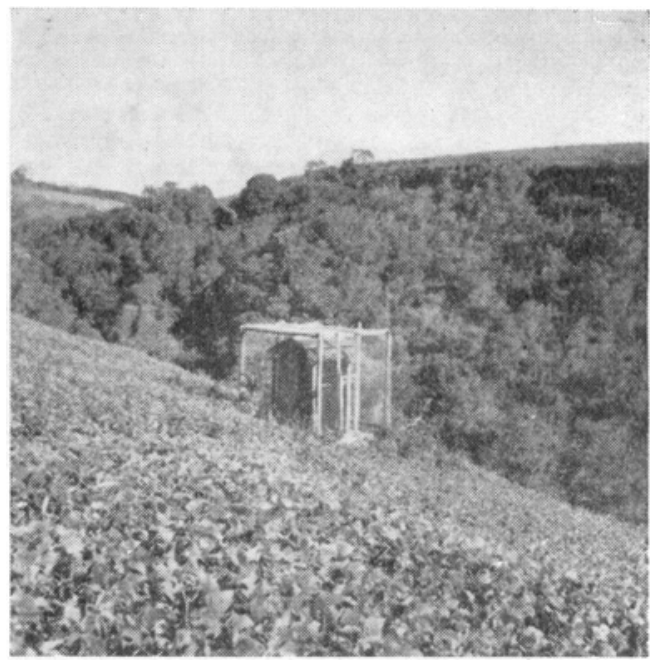

Fig. 11

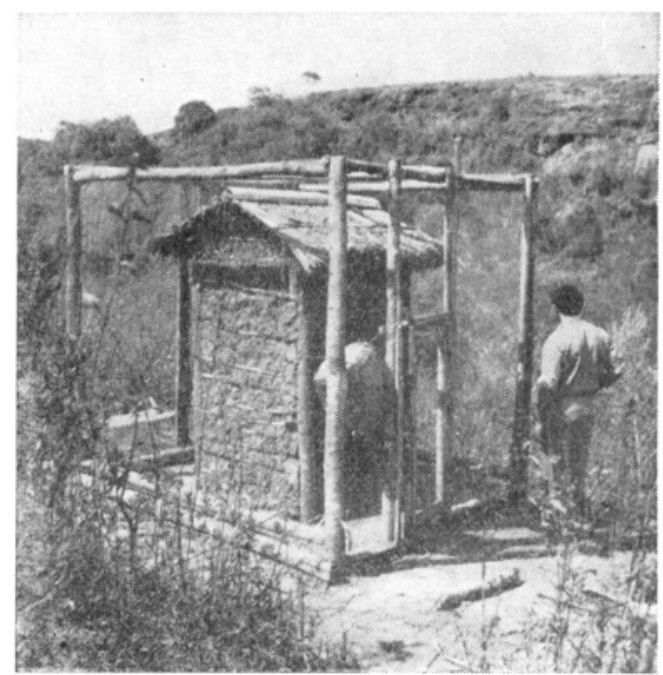

Figs. 11 e 12 - Galinheiro experimental, construído a cêrca de 200 metros da casa mais próxima. A fig. 12 mostra, no fundo, um conjunto de mata residual.

Finalmente, sôbre a possível manuten. ção ou introdução do parasito no meio domiciliar, decidiu-se proceder ao exame 
FORATTINI, O. P. et al. - Infestação domiciliar por Triatoma infestans e alguns aspectos epldemiológicos da tripanossomose. Rev. Saúde públ., S. Paulo, 3(2):159-172, dez. 1969.

dos animais domésticos. Nesse particular, foram escolhidos os cães e gatos nascidos ou introduzidos após o expurgo realizado em dezembro de 1968. Dessa maneira, todos os animais nessas condições, encontrados nos 25 domicílios focalizados neste trabalho, foram sistemàticamente submetidos ao xenodiagnóstico.

\section{R E S U T T D O S}

Infestação domiciliar - Como já se referiu, foram testados 30 edifícios mediante a colocação, em 26 de fevereiro de 1969, de duas caixas em cada um (CX). Daí resultou no emprêgo total de 60 dêsses abrigos artificiais. Daquelas construções, 25 eram casas para residência e 5 eram abrigos para animais domésticos. Decorrida uma semana, a primeira leitura foi levada a efeito a 4 de março de 1969 e a ela seguiram-se outras, rigorosamente semanais, até o total de nove. Depois desta, foi realizada uma última leitura isolada, em 4 de junho de 1969, decorrido pois, um mês da nona semana, três meses da instalação das caixas e cêrca de seis do expurgo seletivo de dezembro de 1968. O motivo dessa derradeira inspecção prendeu-se ao interêsse em detectar possíveis informaçóes, após tempo prolongado. Todo edifício foi considerado positivo, a partir da semana em que, pelo menos uma das caixas revelou algum dos indícios já referidos linhas atrás.

A Tabela 1 reune os resultados gerais obtidos. No que concerne ao rociamento seletivo de XII.68, os dados encontram-se expostos na Tabela 2. Deve-se assinalar que, nesta última, não figuram dois dos edifícios, pois trata-se das casas novas correspondentes aos números 8 (17A) e $21(37 \mathrm{~A})$. Por isso mesmo, elas não foram objeto de selecionamento para o expurgo supracitado. E por essa razão que a análise apresentada a seguir, levou em conta 28 e não os 30 edifícios já mencionados.

Pela observação de tais resultados pode-se verificar que, dos 19 edifícios rociados, 11 mantiveram-se negativos ao exame pelas caixas, enquanto que 8 voltaram a revelar-se positivos. Dêstes últimos, 7 eram casas e 1 anexo. Por outro lado, das 9 construções não expurgadas, por terem sido consideradas negativas, 3 revelaram posteriormente a presença da infestação. Estas últimas foram representadas por casas.

Dessa maneira, o estado de infestação por triatomíneos, referente a êsses edificios que era de 19 positivos e 9 negativos antes do expurgo, passou a ser de 11 para os primeiros e 17 para os segundos, após o mesmo. Pela análise estatística pode-se verificar que, em virtude do número total de construçōes submetidas ao exame ter sido de 28, e considerando-se a casela correspondente a $\mathbf{C X}(+) / \mathbf{E D}$ (-), a freqüência esperada no caso de independência, seria de 3,535.* Assim sendo, optando-se pelo teste exato de Fischer, para testar a ocorrência de associação entre a presença de positividade $e$ ausência de rociamento nos edifícios, verificou-se que, para um nível de significância de $5 \%$, tal hipótese deve ser rejeitada. E isso porque, para aceitá-la, na citada casela deveriam ser esperados valores iguais ou superiores a 6,0 . Por conseguinte, as proporçóes obtidas para prédios expurgados ou não expurgados, não diferiram significativamente. 0 que equivale a dizer que não houve mudança sensível na situação pré e pós-rociamento com BHC.

No que concerne ao cálculo do grau de infestação dêsses edifícios, adotou-se o mesmo critério de Gómez-Núñez já exposto em trabalho anterior (ForatTINI, Juarez \& CorrêA ${ }^{5}$, 1969). Assim sendo, considerando o conjunto das 60 caixas (duas para cada um dos 30 edifícios), 
FORATTINI, O. P. et al. - Infestação domiciliar por Triatoma infestans e alguns aspectos epidemiológicos da tripanossomose. Rev. Saúde públ., S. Paulo, 3(2):159-172, dez. 1969.

TA B E L A 1

Resultados obtidos no Bairro da Ilha, com a colocação das caixas (CX) seguida de 9 inspecçóes semanais e uma realizada três meses depois

\begin{tabular}{|c|c|c|c|c|c|c|c|}
\hline Edificio * & Casa & Anexo & $\begin{array}{l}\text { Expurgo } \\
\text { seletivo } \\
\text { XII/68 }\end{array}$ & $\mathrm{CX}$ & $\begin{array}{c}\text { Semana } \\
\text { inicial } \\
(+)\end{array}$ & $\begin{array}{c}\text { Critério } \\
(+)\end{array}$ & $\begin{array}{l}\text { Tipo de } \\
\text { construção }\end{array}$ \\
\hline $1(12)$ & $\mathbf{x}$ & & - & - & & & b \\
\hline 2(12) & & $x$ & - & - & & & b \\
\hline $3(14)$ & $x$ & & + & + & $3 . a$ & $\mathbf{F}$ & b \\
\hline $4(15)$ & $x$ & & + & - & & & b \\
\hline $5(16)$ & $\mathbf{x}$ & & + & + & $3 . a$ & Fo & b \\
\hline $6(17)$ & $\mathbf{x}$ & & + & - & & & b \\
\hline $7(17)$ & & $\mathbf{x}$ & + & - & & & $\mathbf{b}$ \\
\hline $8(17 A)$ & $\mathrm{x}$ & & - & + & $6 .^{\mathrm{a}}$ & FNA & bn \\
\hline $9(18)$ & $\mathbf{x}$ & & + & - & & & $\mathbf{b}$ \\
\hline $10(19)$ & $\mathbf{x}$ & & + & - & & & $\mathrm{m}$ \\
\hline 11(19) & & $x$ & + & - & & & $\mathrm{t}$ \\
\hline $12(22)$ & $\mathbf{x}$ & & - & + & 3 meses ** & $\mathbf{F}$ & b \\
\hline $13(23)$ & $\mathbf{x}$ & & + & - & & & b \\
\hline $14(23)$ & & $\mathrm{x}$ & + & + & $3 a^{a}$ & $\mathbf{F}$ & b \\
\hline $15(24)$ & $\mathbf{x}$ & & + & + & $8 .{ }^{a}$ & $\mathbf{F}$ & b \\
\hline $16(25)$ & $\mathrm{x}$ & & + & + & $2 . \mathrm{a}$ & $\mathbf{F}$ & b \\
\hline $17(28)$ & $\mathrm{x}$ & & + & + & $2 .{ }^{\mathrm{B}}$ & $\mathbf{F}$ & $\mathbf{b}$ \\
\hline $18(29)$ & $\mathrm{x}$ & & - & - & & & $\operatorname{tr}$ \\
\hline $19(30)$ & $\mathbf{x}$ & & - & + & $2 .{ }^{a}$ & FNE & $\mathbf{b}$ \\
\hline $20(32 A)$ & $\mathrm{x}$ & & + & - & & & $\mathrm{b}$ \\
\hline $21(37 \mathrm{~A})$ & $\mathbf{x}$ & & - & + & $2 .^{2}$ & FN & bn \\
\hline $22(38)$ & $\mathrm{x}$ & & + & + & $2 .^{\mathrm{a}}$ & $\mathbf{F}$ & b \\
\hline $23(38 A)$ & $x$ & & + & - & & & b \\
\hline 24(39) & $\mathrm{x}$ & & - & - & & & $\mathbf{b}$ \\
\hline $25(40)$ & $\mathrm{x}$ & & - & + & $1 . \mathrm{a}$ & $F$ & b \\
\hline $26(41)$ & $\mathbf{x}$ & & - & - & & & $\mathbf{b}$ \\
\hline $27(42)$ & $\mathrm{x}$ & & + & - & & & b \\
\hline $28(48)$ & $x$ & & - & - & & & b \\
\hline $29(50)$ & $x$ & & + & + & $6 .{ }^{a}$ & $F$ & $\mathbf{b}$ \\
\hline \multirow[t]{2}{*}{$30(50)$} & & $\mathbf{x}$ & + & - & & & b \\
\hline & 25 & 5 & $19(+)$ & $13(+)$ & & & \\
\hline
\end{tabular}

* Entre parênteses o número correspondente ao Reconhecimento Geográfico.

** Correspondente a $4 / \mathrm{VI} / 69$.

Legendas: $\quad F=$ fezes; $N=$ ninfa; $A=$ adulto; $O=$ ôvo; $E=$ exúvia; $b=$ de barro; $b n=$ de barro e nova; $t=$ de tijolo; $t r=$ de tijolo rebocado; $m=$ de tábua. 
FORATTINI, O. P. et al. - Infestação domiciliar por Triatoma infestans e alguns aspectos epidemiológicos da tripanossomose. Rev. Saúde públ., S. Paulo, 3(2):159-172, dez. 1969.

T A B E L A 2

Resultados obtidos com as caixas (CX), em relação ao expurgo seletivo de XII.68

\begin{tabular}{rr|r|r} 
& CX (+) & CX (-) & Total \\
\hline ED (-) & 3 & 6 & 9 \\
ED (+) & 8 & 11 & 19 \\
\hline Total & 11 & 17 & 28 \\
\hline
\end{tabular}

CX $(t)$ - edificios positivos ao exame pelas caixas.

CX (-) - edificios negativos ao exame pelas caixas.

ED $(+)$ - edificios expurgados.

ED (-) - edificios não expurgados.

calculou-se a percentagem de positividade obtida até a $2 .{ }^{a}$ semana de leitura. A Tabela 3 apresenta os dados observados nessas duas semanas.

T A B E L A 3

Números de casas, anexos e caixas positivos, revelados nas duas primeiras semanas de observação

\begin{tabular}{c|c|c}
\hline $\begin{array}{c}\text { Semanas * } \\
1 .{ }^{a} / 2 . a\end{array}$ & Casas & Caixas \\
\hline
\end{tabular}

\begin{tabular}{lll}
$2(-) / 1(+) 1(-)$ & 4 & 4 \\
$1(+) 1(-) / 2(+)$ & 1 & 2 \\
$2(+) / 2(+)$ & 1 & 2 \\
\hline Total & 6 & 8
\end{tabular}

* - Os sinais (-) e (+) significam caixa negativa e positiva. $O$ número que os precede indica o número de caixas.

Por conseguinte, verificou-se que até a $2 .^{\text {a }}$ semana, de 60 caixas, 8 revelaram-se positivas. Isso significa percentagem de positividade correspondente a $13,4 \%$. A sua divisão por 2 (correspondente ao número de semanas de observação), resultou no seguinte índice de infestação:

$$
\frac{13,4}{2}=6,7
$$

O critério adotado agrupa êsses valores em classes de cinco unidades, da seguinte maneira:

\begin{tabular}{|c|c|}
\hline Tipo & Classe \\
\hline I & 0 a 4 \\
\hline II & 5 a 9 \\
\hline III & 10 a 14 \\
\hline IV & 15 a 19 \\
\hline
\end{tabular}

Assim sendo, o índice de infestação do Bairro da Ilha, após o expurgo de XII. 68, corresponde ao Tipo II. Comparado com aquêle que foi anteriormente apurado (Forattini, Juarez \& Corrêta ${ }^{5}$, 1969) e que foi calculado como sendo do Tipo III $(12,9)$, parece ter havido alguma redução.

Investigações sôbre focos naturais Foram capturados e examinados, mediante o xenodiagnóstico, 744 mamíferos dos quais, a grande parte foi constituída por roedores. A distribuição específica foi a seguinte:

Akodon arviculoides

Oryzomys nigripes

186

Euryzygomatomys guiara

48

Oxymycterus quaestor

Rattus rattus

Didelphis marsupialis

Didelphis azarae

Nectomys squamipes

Rattus norvegicus

Roedores indeterminados

Tot a l. 
FORATTINI, O. P. et al. - Infestação domiciliar por Triatoma infestans e alguns aspectos epidemiológicos da tripanossomose. Rev. Saúde públ., S. Paulo, 3(2):159-172, dez. 1969.

Dêsse total, foram obtidos apenas 2 resultados positivos, correspondentes a xenodiagnósticos praticados em dois roedores das espécies Akodon arviculoides e Oryzomys nigripes.

No que concerne à pesquisa de ecótopos silvestres, que abrigassem possíveis focos naturais da parasitose, chegou-se a resultados igualmente pobres. Nesse sentido, foram pesquisados, com a maior minúcia possível, cêrca de algumas centenas de ambientes, tais como, ninhos de aves, tocas de animais, no solo e em árvores, troncos caídos, secos ou semi-apodrecidos, árvores sêcas, copas de palmeiras, troncos secos de palmeiras, touceiras de arbustos diversos e mourões de cêrca. Os únicos encontros positivos foram obtidos em 28 de maio e 11 de junho de 1969. O primeiro dêles foi em tronco sêco e ôco de palmeira, que servia como mourão de cêrca na margem da estrada interna dessa localidade e no qual foram capturadas duas ninfas de Triatoma infestans. Alí também foram encontrados ninhos de aves, abandonados. $\mathrm{O}$ segundo achado foi levado a efeito em tronco de árvore semi-apodrecido e sêco, situado em terreno de pastagem e distante cêrca de 500 metros da casa mais próxima. Em anfractuosidades e cavidade dêsse ecótopo foram capturados um adulto macho, uma ninfa de quarto estádio e dois ovos da mesma espécie de triatomíneo (Figura 13). Dêstes últimos, sòmente um eclodiu, depois de levado ao laboratório. Nesse ecótopo foi possível ainda verificar a presença de ninhos de roedores, com sinais sugestivos de ocupação recente. Todos êsses exemplares de triatomíneos mostraram-se negativos ao exame para pesquisa da infecção natural.

Quanto à tentativa de detectar possível dispersão ativa por parte do Triatoma infestans, mediante a construção de galinheiro, foi inteiramente infrutífera. Êsse ecótopo artificial foi instalado a 28 de agôsto de 1968 , a cêrca de 200 metros da casa mais próxima, e submetido a inspecçōes semanais ininterruptas. Decorrido quase um ano, ou seja, a 6 de agôsto de 1969, continuava negativo para triatomíneos.

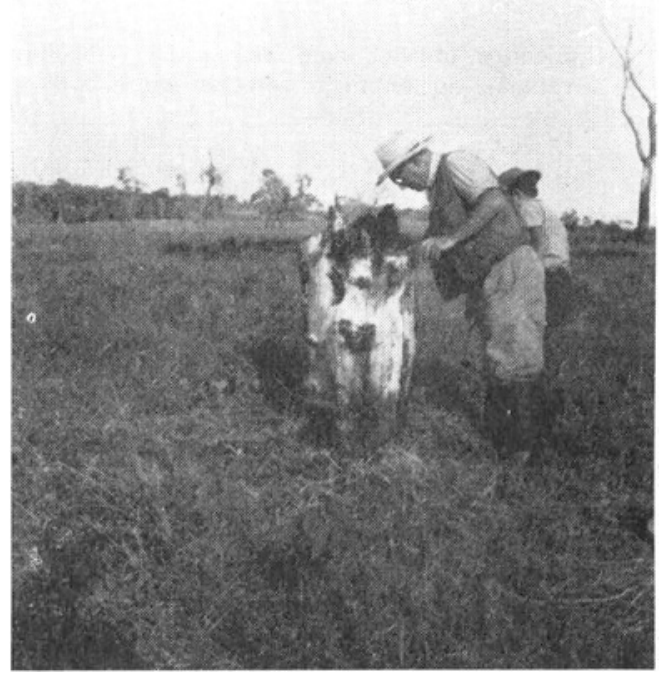

Fig. 13 - Tronco de árvore, cortado e semi-apodrecido, onde foram encontrados ninhos de roedores e algumas formas de Triatoma infestans.

Manutenção da inferção no ambiente domiciliar - Após a realização do expurgode dezembro de 1968, procurou-se obter algum dado que informasse sôbre a continuidade da transmissão ou da manutençãoda parasitose no ambiente domiciliar das casas que constituíram objeto dêste trabalho. Para tanto procedeu-se ao exame, através o xenodiagnóstico dos cães e gatos nascidos ou introduzidos no ambiente dessas: residências, no primeiro semestre de 1969. Isso correspondeu a período imediatamen-te seguinte ao do supramencionado rociamento. Os dados obtidos encontram-se resumidos na Tabela 4 .

A observação dêsses resultados mostra que, de um total de 12 animais jovens, constituídos por 7 cães e 5 gatos, dois: espécimens dêstes últimos revelaram-se infectados. O primeiro dêles foi encontrado na casa $6(17)$ a qual tinha sido desinsetizada por ocasião do supracitado expurgo e onde o exame, pelo método das caixas de Gómez-Núñez, se revelou negativo. Esse animal tinha a idade de um: 
FORATTINI, O. P. et al. - Infestação domiciliar por Triatoma infestans e alguns aspectos eptdemiologicos da tripanossomose.. Rev. Saúde públ., S. Paulo, 3(2):159-172, dez. 1969.

T A B E L A 4

Resultados obtidos com o xenodiagnóstico (XD) praticados em animais domésticos, nascidos ou introduzidos no Bairro da Ilha, depois de dezembro de 1968

\begin{tabular}{|c|c|c|c|c|c|}
\hline \multicolumn{2}{|c|}{ Edificios * } & \multirow{2}{*}{ Cães } & \multirow{2}{*}{$\mathrm{XD}$} & \multirow{2}{*}{ Gatos } & \multirow{2}{*}{$\mathbf{X D}$} \\
\hline Casa & $c x$ & & & & \\
\hline $5(16)$ & + & 2 & - & & \\
\hline $6(17)$ & - & & & 1 & + \\
\hline $9(18)$ & - & & & 1 & - \\
\hline $12(22)$ & + & 1 & - & 1 & - \\
\hline $13(23)$ & - & 1 & - & & \\
\hline $16(25)$ & + & 1 & - & & \\
\hline $18(29)$ & - & 1 & - & & \\
\hline $21(37 A)$ & + . & 1 & - & & \\
\hline $28(48)$ & - & & & 1 & - \\
\hline $29(50)$ & + & & & 1 & + \\
\hline \multicolumn{2}{|c|}{ Total } & 7 & - & $\mathbf{5}$ & $2(+)$ \\
\hline
\end{tabular}

* Vide Tabela 1.

mês, quando foi submetido ao xenodiagnóstico a 16.IV.69. Diante do resultado positivo, procurou-se verificar a possível origem congênita dessa infecção. E isso pôde ser feito, uma vez que a gata mãe habitava a mesma casa. Assim sendo, foi ela submetida ao mesmo exame a 4.VI.69 e o resultado foi também positivo, o que trouxe boas razōes para supor que tivesse ocorrido aquêle tipo de transmissão. 0 segundo animal que se mostrou portador da parasitose, foi um gato de três meses de idade, quando do xenodiagnóstico levado a efeito a 4.VI.69. Foi êle encontrado na casa $29(50)$, objeto também de expurgo em dezembro, mas positiva ao exame posterior pelas caixas. Todavia, êsse animal não tinha nascido ali, mas sim fôra recentemente trazido de outra localidade vizinha.

Diante dêsses fatos, é de se supor que a parasitose, pelo menos lançando mão dos animais domésticos, encontrou oportunidade de se manter e introduzir no Bairro da Ilha. E isso logo após a aplicação do. expurgo seletivo das habitações pelo BHC.

\section{COMENTARIOS E CONCLUSOES}

Face aos resultados obtidos nesta investigação, supomos ser lícito proceder a co. mentários e chegar a algumas conclusóes.

Inicialmente, pensamos que o método. de Gómez-Núñez é bastante útil para a avaliação dos resultados obtidos com 0 rociamento empregado no combate ao Triatoma infestans. Como se pode ver pela análise da Tabela 1 , essas observações concordam com as de Gómez-NúNẼEZ ${ }^{\text {* }}$ (1965) e de GAMBôA ${ }^{8}$ (1965) relativas ao Rhodnius prolixus. Assim pois, verificou-se que a leitura até a 8.a semana tem a maior probabilidade de detectar a infestação. Com efeito, prolongando-se de maneira considerável o tempo de observação além dêsse período, apenas mais 
FORATTINI, O. P. et al. - Infestação domiciliar por Triatoma infestans e alguns aspectos epidemiológicos da tripanossomose. Rev. Saúde públ., S. Paulo, 3(2):159-172, dez. 1969.

uma casa revelou-se infestada por triatomíneos. Foi a de número $12(22)$ cujas caixas mostraram-se positivas sòmente por ocasião da última leitura isolada, levada a efeito a 4.VI.69.

Além disso, parece que essas caixas de papelão são bem aceitas, como abrigo, por parte daquela espécie de triatomíneo. A propósito, tivemos mesmo a portunidade de realizar interessante observação. Ao início dêste trabalho, encontrou-se no edifício de número $19(30)$, uma das caixas empregadas na investigação anterior (Forattini, Juarez \& CorrêA ${ }^{5}, 1969$ ) e que tinha sido esquecida na parede. Essa casa fôra considerada como negativa e portanto, deixou de receber o rociado em XII.68. No entanto, quando se procedeu à instalação das novas caixas, encontrou-se dentro dela várias ninfas de Triatoma infestans algumas das quais engurgitadas, além de cascas de ovos.

É bem verdade que o problema de medir a infestação domiciliar e de avaliar - resultado das desinsetizaçōes, ainda necessita de maiores estudos, pois várias sāo as dificuldades que entravam a sua solução. No entanto, tudo leva a crer que - emprêgo do processo das caixas representa apreciável progresso nesse sentido. $\mathrm{E}$ isso porque, o uso dessa técnica, sôbre ser fácil, uniforme e pouco dispendiosa, mostra ainda apreciável sensibilidade. E a tal ponto que, pelo menos no Bairro da Ilha, permitiu avaliação razoável dos efeitos obtidos com o expurgo realizado em XII.68 mediante o emprêgo de BHC. Nesse particular, como já se viu na apre. sentação dos resultados, é de se conside. rar que êsse rociamento em geral, e o método seletivo em particular, constituem meios de contrôle que ainda deixam muito a desejar. Pode-se obter certa melhoria da situação, principalmente quanto ao índice de infestação, que sofre alguma redução. Contudo, sob o ponto de vista profilático, há necessidade de alguma reconsideração. Tanto mais ao se levar em conta que se trata de processos bastante dispendiosos e de cuja aplicação intensiva não resulta, pelo menos na área estudada, mudança satisfatória no que concerne à presença do Triatoma infestans. Isso nos leva a pensar, com maior ênfase, que o combate a êsse triatomíneo deva ser encaminhado, mais no sentido da melhoria da habitação e menos no uso, cada vez mais intenso e variado, de inseticidas.

No que concerne à presença dos focos naturais, a pesquisa revelou a existência do protozoário em ambiente extradomiciliar, na área que foi objeto das investigações. $\mathbf{O}$ encontro dos roedores $A k o$. don arviculoides e representantes do gênero Oryzomiys, como portadores naturais da infecção, já tinha sido assinalado em outras regiões. $\mathbf{O}$ primeiro foi observado infectado, no município de Ribeirão Prêto, Estado de São Paulo (Ferriolli F. \& Barretto 4 , 1965). Quanto ao segundo, trata-se do encontro de Oryzomys capito laticeps, com a mesma parasitose, no município de Uberaba, Estado de Minas Gerais (Funayama \& Barretto ${ }^{7}, 1969$ ). Assim sendo, e embora deixando para outra oportunidade a realização de exames mais minuciosos sôbre as amostras isoladas no Bairro da Ilha, é de se suspeitar que se trate de representantes de Trypanosoma cruzi. Em primeiro lugar, por terem sido isoladas mediante o emprêgo do xenodiagnóstico. Em segundo lugar, em virtude de achados semelhantes obtidos em outras áreas por outros autores. Dessa maneira, o presente encontro seria a confirmação da existência de infecção natural em Akodon arviculoides e o registro da espécie Oryzomys nigripes como outro possível reservatório.

Quanto ao Triatoma infestans, os escassos achados já relatados, levam à suposição de que, pelo menos no Bairro da Ilha, a população dêsse triatomíneo apresente baixa valência ecológica. Com efei. to, parece que ali ela possui pouca tendência a abandonar o ecótopo representado pelo ambiente domiciliar humano. $E$ isso não apenas pelo fato do hemíptero ter sido observado sòmente em duas situaçôes extradomiciliares, mas também 
FORATTINI, O. P. et al. - Infestaçăo domiciliar por Triatoma infestans e alguns aspectos epidemiológicos da tripanossomose. Rev. Saúde. públ., S. Paulo, 3(2):159-172, dez. 1969.

pelo pequeno número de exemplares capturados. Contudo, é de se pensar que, mesmo nesta área, êle não tenha perdido completamente a capacidade de adaptação a ambientes naturais. Nesse particular convém assinalar que, em alguns municípios da região nordeste do Estado de São Paulo, êsse triatomíneo tem sido observado em ecótopos silvestres, semelhantes aos encontrados nesta pesquisa, embora com freqüência maior (BARRETTo, S|QueIra \& CorrêA ${ }^{3}, 1963$; Barretto \& Ferrioli F. ${ }^{\circ 2} ;$ 1964; Barretto $^{1}$, 1966) .

De qualquer maneira, tudo indica que também no Bairro da Ilha ocorre a presença de focos naturais de tripanossomose. O seu significado, em relação ao ambiente humano, sòmente poderá ser avaliado após maiores e mais prolongadas investigações.

Finalmente, no que concerne à persistência ou à introdução do parasito nas casas que foram objeto do presente trabalho, os resultados obtidos permitem também algumas considerações. $O$ objetivo principal foi o de verificar se, logo após o rociamento, poderia ocorrer algo de nôvo nesse sentido. Por isso escolheu-se os animais domésticos, nascidos ou introduzidos, logo depois daquela data, ou seja, no decurso do primeiro semestre de 1969. Pensou-se que, assim procedendo, poderia ocorrer a possibilidade de surpreender alguma nova transmissão ou introdução do Trypanosoma cruzi.

Os resultados já relatados permitem, em primeiro lugar, supor que, mesmo na ausência de triatomíneos, a transmissão possa persistir por outros meios. No caso, parece ter sido a via congênita. E que se depreende da observação levada a efeito na casa $6(17)$, com um gato jovem infectado, cuja mãe também se revelou positiva ao xenodiagnóstico. Em segundo lugar, o que se observou no domicílio $29(50)$, evidenciou a possibilidade de introdução de animais infectados procedentes de outras áreas. No caso particular, o encontro foi bem significativo pois se tra- tava de casa que acusou persistência da infestação triatomínica.

Em resumo, as investigações levadas a efeito no Bairro da Ilha mostraram, de maneira bastante sugestiva, que o combate ao Triatoma infestans através o expurgo seletivo com emprêgo de $\mathrm{BHC}$, não surtiu o efeito desejado. A isso deve-se acrescentar a ocorrência de novas infecções pelo menos nos animais domésticos, imediatamente após a execução da desinsetização. Ao lado disso, a possibilidade de existência de focos naturais da parasitose. Levando-se em consideração tais fatôres, não é difícil concluir que a profilaxia da doença de Chagas deverá sofrer, necessàriamente, orientação outra que não apenas o simples uso de inseticidas.

Forattini, O. P. et al. - House infestation by Triatoma infestans and some epidemiologic aspects of American trypanosomiasis in a certain area of the State of São Paulo, Brazil. Rev. Sanide públ., S. Paulo, 3(2) :159-172, dez. 1969. SuMMARY - Epidemiological investigations about American trypanosomiasis (Chagas' disease) in the area of Bairro da Ilha, County of Salto de Pirapora, S. Paulo State, Brazil, are reported. Twenty eight houses submited to the selective technique of insecticide spraying (BHC), was tested by Gómez-Núñez method. The results obtained showed that several houses still retains with infestations in a proportion not significatively different to the before the one noticed insecticide treatment. Only a reduction of the general infestation index was obtained. Beside this some evidence showed the possibility of the occurrence of natural foci of the infection. The rodents Akodon arviculoides and Oryzomys nigripes were found naturally infected by the use of xenodiagnosis technique. In the house environment, infections was found to persist, through the examination of new born or new introduced dogs and cats, little after the houses selective desinsetization. Two cats were found 
FORATTINI, O. P. et al. - Infestação domicillar por Triatoma infestans e alguns aspectos epidemiológicos da tripanossomose.. Rev. Saúde públ., S. Paulo, 3(2):159-172, dez. 1969.

infected, one of them suggest to have adquired the infection by congenital way. 'The other positive animal, was introduced from another area. So we conclude by the necessity of a thorough revision of the prophylactic methods of Chagas' disease based only on the control of triatomids by insecticide use.

\section{A G R A D E I M E N T O S}

Ao Dr. Cory T. de Carvalho, da Secretaria da Agricultura do Estado de São Paulo, pela identificação dos mamíferos capturados; ao Dr. Naim Sauaia, da Faculdade de Higiene e Saúde Pública da USP, pelo auxílio prestado na análise estatística; e ao Sr. Agenor C. dos Santos, da Cidade de Salto de Pirapora, pelas facilidades proporcionadas e que muito contribuiram na realização destas investigações.

\section{REFERENCIAS BIBLIOGRAFICAS}

1. BARRETO, M. P. - Aspectos da epidemiologia da tripanossomose americana, infecção com focos naturais, com especial referência à regiāo Nordeste do Estado de São Paulo. Săo Paulo, 1966. (Tese - Fac. Farm. Odontol. Ribeirăo Prêto - mimeografada).

2. BARRETTO, M. P. \& FERRIOLLI FILHO, F. - Estudos sôbre reservatórios e vectores silvestres do Trypanosoma cruzi. IV - Infeccão natural do Triatoma infestans, encontrado em ecótopos silvestres, por tripanossomo semelhante ao T. cruzi. Rev. Inst. Med. trop. S. Paulo, 6:219-224, set./out. 1964.
3. BARRETTO, M. P.; SIQUEIRA, A. F. \& CORREA, F. M. A. - Estudos sôbre reservatórios e vectores silvestres do Trypanosoma cruzi. I - Encontro do Triatoma infestans (Hemiptera, Reduvildae) em ecótopos silvestres. Rev. Inst. Med. trop. S. Paulo, 5:289-293, nov./dez. 1963.

4. FERRIOLLI FILHO, F. \& BARRETTO, M. P. - Estudos sôbre reservatórios e vectores silvestres do Trypanosoma cru$z i$. VI - Infecção natural do roedor Akodon arviculoides cursor (Winge, 1885) por tripanossomo semelhante ao Trypanosoma cruzi. Rev. Inst. Med. trop. S. Paulo, y:72-81, mar./abr. 1965.

5. FORATTINI, O. P.; JUAREZ, E. \& CORREA, R. R. - Medida da infestação domiclliar por Triatoma infestans. Rev. Sañde públ., S. Paulo, 3:11-16, Jun. 1969.

6. FREITAS, J. L. P. de - Importancia do expurgo seletivo dos domicllios e anexos para a profilaxia da moléstia de Chagas pelo combate aos triatomineos. Arq. Hig., S. Paulo, 28:217-272, set. 1963.

7. FUNAYAMA, G. K. \& BARRETTO, M. P. - Estudos sôbre reservatórios e vectores silvestres do Trypanosoma cruzi. XXXIV - Infecção natural do rato, Oryzomys capito laticeps (Lund, 1841) pelo T. cruzi. Rev. bras, Biol., 29:163-173 , jun. 1969.

8. GAMBOA C., J. - Comprobación de la presencia de Rhodnius prolixus en la vivienda rural. Bol inf. Dir. Malar. San. $a m b ., 5: 270-274$, dic. 1965.

9. GOMES-NUNEZ, J. C. - Desarrollo de un nuevo método para evaluar la infestación intradomiciliaria por Rhodnius prolixus. Acta cient. venez., 16:26-31, 1965. 